\title{
Health facilities' readiness to provide friendly reproductive health services to young people aged 10-24 years in Wakiso district, Uganda
}

\author{
Bukenya N.Justine ${ }^{1}$, Mulogo Edgar ${ }^{2}$, Kibira S.Simon Peter ${ }^{1}$, Muhumuza Christine ${ }^{3}$, and Atuyambe M.Lynn ${ }^{1}$ \\ ${ }^{1}$ Department of Community Health, Makerere University School of Public Health, College of Health Sciences \\ ${ }^{2}$ Department of Community Health, Mbarara University of Science and Technology
}

Submission: June 23, 2017; Published: September 25, 2017

*Corresponding author: Justine N Bukenya, Department of Community Health, Mbarara University of Science and Technology, Uganda; Email: jbukenya@musph.ac.ug

Abstract

Background: While adolescents aged 10-19 years make up to 23.3\% of Uganda's population, health facilities offering adolescent sexual and reproductive health services are few and do not fully address young people's needs. There is a paucity of evidence on the extent to which Ugandan health facilities in rural and peri-urban settings offer these services. This study assessed the readiness of health facilities to provide friendly reproductive health services to young people in rural and peri-urban contexts in Uganda.

Methods: The data for this paper come from a cross-sectional study that used quantitative and qualitative approaches to capture information. The study was conducted in 2012 in 32 health facilities in Wakiso district. It involved reviewing health facility records to assess client load for reproductive health services in the three months preceding data collection as well as key informant interviews with health managers and providers to identify gaps in service provision for young people. Quantitative data were entered into Epi-data and analysed using STATA10, while qualitative data were analysed using content analysis.

Findings: Among the 32 facilities visited; 41\% (13/32) young people had to walk a distance of more than $5 \mathrm{kms}$ to access them, only one health centre had a separate space for providing services for adolescent clients and all facilities visited lacked a waiting room exclusive for young people. On the other hand, only 29\% (9/32) and 22\% (7/32) of the health facilities reported sufficient supplies and equipment respectively that are necessary for providing services that meet the needs of young people. Deliveries within the facilities were very low representing just 23\% (1843/7975) of the number of young people who sought antenatal care services. Moreover 19\% (6/32) of the facilities were not routinely screening for STIs yet in facilities where screening was being done, individuals younger than 15 years were being diagnosed with STIs. In addition, most facilities $86 \%$ (27/32) provided restricted family planning services to young people. No facility reported providing services responding to gender based violence while most facilities indicated verbal referrals for these services.

Conclusion: The findings of this paper suggest the need for training and equipping health care workers in order to improve the provision of reproductive health services to young people.

Keywords: 'Young people'; 'Readiness; 'Reproductive health services'; Rural; Peri-urban; Uganda

Abbreviations: FP: Family Planning; HC: Health Centre; HSSIP: Health Sector Strategic and Investment Plan; PEs: Peer Educators; SRH: Sexual Reproductive Health; WHO: World Health Organization

\section{Background}

Worldwide, there are over 1.8 billion young people, of whom $90 \%$ live in low income countries [1]. Young people are defined as individuals aged 10-24 years, encompassing adolescents aged 10-19 years as well as youth aged 15-24 years. The proportion of the world's young people aged 12-24 years living in Africa is expected to rise from $18 \%$ in 2012 to $28 \%$ by 2040 [1]. It is estimated that between $30-50 \%$ of the population in low income countries is under 20 years old [2]. Mortality rates amongst young people in sub Saharan Africa are four times higher than anywhere else in the world [3]. The causes of death of young women include conditions related to problem behaviors such as risky sexual intercourse which leads to early or unwanted pregnancy that are in turn associated with induced abortions [4-6].

Although adolescent birth rate has declined in all regions of the world since 1990, it has been rising in Africa while the level has also remained high at 101 births per 1,000 women [7]. There are, however, wide variations in adolescent birth rate in the 


\section{Global Journal of Reproductive Medicine}

region with Uganda, for example, having an adolescent birth rate of 134 births per 1,000 women which is higher than the average for Africa [8].

Investments aimed at improving the Sexual and Reproductive Health (SRH) of young people can substantially reduce unwanted pregnancies, Sexually Transmitted Infections (STIs) and HIV infection among this segment of the population. The risk of unintended pregnancy among young people is attributable to high unmet need for family planning as well as negative attitudes of health care workers who uphold societal norms that disapprove of the provision of contraceptives to unmarried adolescents [2]. Existing evidence indicates that strengthening the health care system by ensuring availability of well trained personnel and adequate infrastructure is key to preventing health problems among young people, promoting positive SRH behaviors and improving quality of care [9].

According to the WHO 2009 guidelines, youth friendly health services represent an approach which combines the qualities that young people demand, with the recommended standards that have to be achieved in the best public health services [10]. Reproductive health services should be provided by trained persons who have respect for young people and honour privacy and confidentiality. The guidelines emphasise that adequate time for client and provider interaction should be availed. Health facilities offering friendly services to young people should have: peer counsellors, convenient opening hours for all young people, comfortable surrounding with short waiting times and no overcrowding. In addition the facilities should provide a wide range of services for young men and women, as well as be in position to make necessary referrals. Such services should be equitable, accessible, acceptable, effective and appropriate for adolescents [5].

A number of studies have investigated factors related to availability, access, and utilization of services for adolescents have been investigated in many Sub-Saharan countries including Kenya [11,12], Ethiopia [13] Nigeria, Ghana, Malawi and Burkina Faso [14]. Findings from these studies show that available services for young people are not comprehensive enough to focus on all of the SRH needs of young people. Services are generally centred within the traditional "adult" clinical settings and are often viewed as inappropriate sources of care by adolescents and youth. Besides, health workers often refuse to give unmarried young people contraceptive information and services because they do not approve of pre-marital sexual activity, even in countries where there are no related legal restrictions [15-17]. Other barriers include stock outs of contraceptives, costs for transport and unfriendly service provision [18].

The existing Adolescent Health Policy Guidelines and Service Standards emphasize that adolescents should be given contraceptive information and services they need with no restriction at all levels of health service delivery points
[19]. From the 2010/11-2014/15 in the Uganda Health Sector Strategic and Investment Plan (HSSIP), it is documented that only $10 \%$ of health facilities in the country offered adolescentfriendly services according to WHO guidelines although the Government's aim was to increase it to $75 \%$ by 2015 [20].

The Government's goal of ensuring that three-quarters of the health facilities in the country offer youth friendly services does not take into account the disparities that exist between urban, peri-urban and rural areas regarding the availability of requisite resources. Moreover, it could be that the $10 \%$ of health facilities that were considered to offer youth-friendly services in the 2010/11-2014/15 HSSIP were disproportionately located in urban areas given that historically, most development initiatives have been concentrated in urban settings. While about $23.3 \%$ of Uganda's population consists of adolescents [8], adolescent sexual and reproductive health services remain limited and do not address the needs of young people.

There is therefore limited understanding of the capacity of health facilities located in peri-urban and rural settings to offer services that meet the needs of young people. This study assessed the readiness of health facilities in Wakiso district of Uganda a largely rural district to provide youth friendly SRH services. Understanding the extent to which facilities are prepared to offer youth-friendly SRH services is important for informing programs aimed at increasing access to and utilization of health care services by young people.

\section{Methods and Design}

A cross sectional study using quantitative and qualitative methods was conducted in Wakiso district in central Uganda in 2012. Wakiso has a population of about 1.4 million people with $92 \%$ of them living in rural areas and $6 \%$ in peri-urban settings. Thirty four percent of the population in Wakiso District is young people aged 10-24 years [21]. Administratively, Wakiso is divided into two counties and one municipality; has 17 sub-counties and 131 parishes with an average household size of 4.1 persons. There are 103 health facilities in Wakiso district. There are 103 health facilities in Wakiso district. Out of these, 4 are hospitals (1 public, 2 Private Not-For-Profit [PN FP] and 1 private for-profit); 5 are Health Centre (H C) Levels IV (4 public and 1PN FP); 37 are H C Levels III (24 public and 13 PN FP); and 57 are H C Levels II (37 public and 20 PN FP)

\section{Data collection}

The WHO quality assessment guide was modified by the study team to for assess health services for adolescent clients [22]. The WHO tool was modified to additionally capture data from records on the number of clients who had attended services in the last three months preceding the survey. The 32 facilities comprised public, private-not-for-profit and private for-profit hospitals and health centres (Levels II to IV). The facilities were sampled according to the level of service delivery. A total of 2 hospitals, $3 \mathrm{H}$ CIVs, $16 \mathrm{H}$ CIIIs and $11 \mathrm{H} \mathrm{CIIs} \mathrm{were} \mathrm{included} \mathrm{in}$ 


\section{Global Journal of Reproductive Medicine}

the study. Higher proportions of hospitals (50\% (2/4)) and HCIV $(60 \%(3 / 5))$ were selected compared to lower facilities because adolescents are likely to seek post-abortion services from such outlets thereby increasing the chances of capturing information on them. The team reviewed clinic records including registers for antenatal, maternity, family planning and post abortion care to assess client load for reproductive health services. Health service providers were interviewed on the range and quality of services provided to young people at their facility.

Twelve Key Informant (KI) interviews were conducted in English language with health managers including district team members and in-charges of Post-Abortion Care (PAC) who represented health service providers. The in-charges of maternal and child health departments were interviewed instead, at facilities where in charge of post-abortion services were unavailable. KIs were selected from the district health team and all strata including hospitals and HCIV, and a few HCIII. The key informant interviews focused on identifying issues affecting young people and the services offered to them. These interviews were also used to identify gaps in service provision for adolescents. Data on the feasibility of conducting an intervention for improving services for young people were also collected.

All tools were pre-tested and modified before being administered by trained research assistants and investigators. Ethical clearance was obtained from Makerere University School of Public Health Research and Ethics Committee (IRB11353) and the Uganda National Council of Science and Technology (SS 2894). Permission was obtained from the district health office and management of the respective health facilities and written informed consent was obtained from the health providers.

\section{Analysis}

The readiness of the facilities to provide reproductive services to young people was based on selected parameters in relation to standards for adolescent friendly clinics [23]. The parameters included location, hours of operation, facility environment (privacy of service areas), availability of commodities and equipment as well as the range of services offered. Data were entered using Epi-data and descriptive analysis done using STATA10 to obtain proportions. The qualitative interviews were audio recorded and transcribed verbatim. The typed transcripts were read several times and manually coded based on the study objective while allowing for open coding as well. Qualitative data were analysed using content analysis technique.

\section{Results}

Background characteristics of the health facilities

The distribution of facilities visited by level, ownership and location is shown in Table 1. Health facilities`readiness to provide reproductive services. The distribution of the parameters used to assess the readiness of health facilities to provide reproductive health services to young people is shown in Table 2.

Table 1: Background characteristics of health facilities $(n=32)$.

\begin{tabular}{|l|c|}
\hline \multicolumn{1}{|c|}{ Variable } & Frequency (\%) \\
\hline Health facility level & $2(6.3)$ \\
\hline Hospital & $3(9.4)$ \\
\hline Health Centre IV & $16(50.0)$ \\
\hline Health Centre III & $11(34.0)$ \\
\hline Health Centre II & $22(68.8)$ \\
\hline Ownership & $9(28.1)$ \\
\hline Public & $1(3.1)$ \\
\hline Private-Not-For -Profit (PNFP) & $28(87.5)$ \\
\hline Private For Profit (PFP) & $4(12.5)$ \\
\hline Location & \\
\hline Rural & \\
\hline Urban & \\
\hline
\end{tabular}

Table 2: Distribution of parameters used to measure health facility readiness to provide

\begin{tabular}{|l|c|c|}
\hline Parameter of readiness (N=32) & (n) \\
\hline Location of facility & 13 & 40.6 \\
\hline Location of facility from public transport stop :> 5kms & \multicolumn{2}{|l|}{} \\
\hline Hours of Operation & 32 \\
\hline Time of opening the clinic from 07.00 to 9.00hrs & 100 \\
\hline Time of closing the clinic from 16.00-18.00Hrs & 19 & 59.4 \\
\hline Separate hours for adolescents & 0 \\
\hline Sign listing services and clinic working hours & 0 \\
\hline Reported convenient hours for adolescents to seek services & 0 \\
\hline 8.00 am -12.00pm & 0 \\
\hline $13.00-17.00 \mathrm{pm}$ & 6 \\
\hline $17.00-20.00 \mathrm{pm}$ & 18.8 \\
\hline No specific time & 50 \\
\hline
\end{tabular}


Global Journal of Reproductive Medicine

\begin{tabular}{|c|c|c|}
\hline \multicolumn{3}{|l|}{ Facility Environment } \\
\hline Having a separate space to provide services for adolescent clients & 1 & 3.1 \\
\hline Having a separate waiting room for adolescent clients & 0 & 0 \\
\hline Presence of counselling area that provides both visual and auditory privacy & 8 & 25 \\
\hline Presence of examination room that provides visual and auditory privacy & 9 & 28.1 \\
\hline Both young men and young women welcomed and served, either for their own needs or as partners & 28 & 87.5 \\
\hline \multicolumn{3}{|l|}{ Adequate commodities and equipment } \\
\hline Supplies sufficient to meet the adolescent’s need & 9 & 28.1 \\
\hline Sufficient equipment for the provision of RH services for young people & 7 & 21.9 \\
\hline \multicolumn{3}{|l|}{ Services offered } \\
\hline $\begin{array}{l}\text { Counseling services: on sexuality, safer sex, pregnancy prevention, and STI and HIV prevention provided (including dual } \\
\text { protection) }\end{array}$ & 20 & 62.5 \\
\hline Condoms to both males \& females & 24 & 75 \\
\hline Pregnancy testing & 23 & 71.9 \\
\hline Screening for STIs & 26 & 81.3 \\
\hline \multicolumn{3}{|l|}{ Provision of Family planning } \\
\hline Restriction of contraceptive methods & 27 & 84.4 \\
\hline Parental or spousal consent required & 27 & 84.4 \\
\hline Minimum age required for adolescents to receive Contraceptives & 24 & 75 \\
\hline Adolescent clients served irrespective of their marital status & 23 & 71.9 \\
\hline \multicolumn{3}{|l|}{ Policies and guidelines } \\
\hline Do clear written guidelines for serving adolescents exist? & None & \\
\hline Are there educational posters displayed? & 12 & 37.5 \\
\hline Are there print materials available for clients to take? & 4 & 12.5 \\
\hline
\end{tabular}

adolescent-friendly services.

Less than half $41 \%(13 / 32)$ of the facilities were located more than $5 \mathrm{kms}$ away from a public transport stop. Half of the facility in-charges $50 \%(16 / 32)$ reported that young people preferred to access services between 13:00 and 17:00 hours with another $16 \%(5 / 32)$ reporting a preference for between 17:00 and 20:00 hours, yet most of the facilities 59\% (19/32) closed between 16.00-18.00 hours. No health worker reported that their facility had separate hours for young people.

Moreover, the majority of the facilities lacked infrastructure and space to provide privacy for young people, with only one facility (HC level III) reporting having a separate space for providing services for young people. No facility had an exclusive waiting room for young people. Similar concerns were made by key informants; "Privacy and confidentiality, is not all that good. I have no appropriate room where I can discuss with young people without interference from other patients and fellow health workers" (Key informant, Nurse, HC III)

"Like for instance during antenatal clinic, the teenage mothers don't want to share with adult mothers, they feel out of place. So if we could allocate particular hours for adolescents or spare a separate place it would make them to feel comfortable. However, the government has to post more staff if we are to provide good services for young people" (Key informant, in charge, HCIV).

Commodities including condoms and contraceptives were reported to be sufficient in only $29 \%$ (9/32) of facilities. Equipment for provision of reproductive health services for young people such as small size speculum, weighing scales, and sphygmomanometer were reported to be sufficient in only $22 \%(7 / 32)$ of health facilities. The managers attributed the inadequate availability of supplies to the current drugs and medical supply system challenges; I don't know what the ministry can do about the current medical supply system; they just bring standard kits without considering the consumption rates for the lower facilities like HC III and HCII. So such facilities cannot order adequate supplies like STI drugs, nor contraceptives to prevent pregnancy (Key informant, District Health team).

Most of the facilities $86 \%$ (28/32) reported welcoming both male and female young people, although the records showed that more females than males received services. Services provided to young people. Data extracted from clinic records revealed a number of services were provided to young people between 10 and 24 years in the three-month period preceding the study and these are shown in Table 3. 
Table 3: Services provided to young people $(10-24$ years) three months preceding the study.

\begin{tabular}{|c|c|c|c|c|c|c|c|c|c|}
\hline \multirow{3}{*}{$\begin{array}{l}\text { Service } \\
\text { provided }\end{array}$} & \multirow{3}{*}{ Total } & \multirow{3}{*}{$\begin{array}{l}\text { Male } \\
\text { n(\%) }\end{array}$} & \multirow{3}{*}{$\begin{array}{c}\text { Female } \\
\text { n(\%) }\end{array}$} & \multicolumn{6}{|c|}{ Age Group } \\
\hline & & & & \multicolumn{2}{|c|}{ 14-0ct } & \multicolumn{2}{|c|}{$15-19$} & \multicolumn{2}{|c|}{$20-24$} \\
\hline & & & & Male n(\%) & Female $n(\%)$ & Male n(\%) & Female n(\%) & Male n(\%) & Female $n(\%)$ \\
\hline $\begin{array}{c}\text { STI } \\
\text { management }\end{array}$ & 138 & $59(43)$ & $79(57)$ & $15(11)$ & $4(3)$ & $7(5)$ & $22(16)$ & $37(27)$ & $53(38)$ \\
\hline $\begin{array}{l}\text { Post abortion } \\
\text { Care }\end{array}$ & 26 & NA & $26(100)$ & NA & 0 & NA & $6(23)$ & NA & $20(77)$ \\
\hline $\begin{array}{c}\text { Sexual Abuse } \\
\text { or Violence }\end{array}$ & 0 & 0 & 0 & 0 & 0 & 0 & 0 & 0 & 0 \\
\hline $\begin{array}{l}\text { Contraception } \\
\text { provision }\end{array}$ & 870 & 0 & $870(100)$ & 0 & 0 & 0 & 199 (23) & 0 & $671(77)$ \\
\hline $\begin{array}{l}\text { Antenatal } \\
\text { Care }\end{array}$ & 7975 & NA & $\begin{array}{l}7975 \\
(100)\end{array}$ & NA & $9(0)$ & NA & $2750(34)$ & NA & $5216(66)$ \\
\hline Postnatal Care & 313 & NA & $\begin{array}{c}313 \\
(100)\end{array}$ & NA & $6(2)$ & NA & $127(41)$ & NA & $180(59)$ \\
\hline Delivery & 1843 & NA & $\begin{array}{l}1843 \\
(100)\end{array}$ & NA & $1(0)$ & NA & $643(35)$ & NA & $1199(65)$ \\
\hline
\end{tabular}

Among the 19 clients aged below 15, a higher proportion of boys (79\%) than girls (21\%) sought treatment for Sexually Transmitted Infections (STI). However in the older age groups, the number of girls seeking STI treatment was higher than the boys. Nineteen percent (6/32) of the facilities were not offering services for routine screening for STIs, yet in other facilities where screening was done; adolescents below 15 years had been diagnosed with STIs. About 23\% (6/26) of females who sought post abortion care were adolescents. No facility reported providing services for gender based violence. Key informants reported women seeking post sexual abuse or violence services were verbally referred elsewhere. Yes we get sexually abused adolescents, but for us here we just refer them to the H/C IV, but some youth fail to go where they have been referred and just go back home because they lack transport (Key informant, Midwife, HCIII)

Although providers in all facilities said that they made referrals for services not offered, they lacked a systematic (back and forth) documented referral mechanism. Adolescents comprised 34\% (2750/7975) and 35\% (643/1843) among mothers aged 24 years and below who sought at least one antenatal care visit and delivery care respectively among in the health facilities included in the survey. The number of deliveries occurring in the health facility was lower than that of women who sought antenatal clinic at least once. Slightly, less than half $41 \%(127 / 313)$ of the young women who attended postnatal clinic were adolescents.

About quarter 23\% (199/870) of the young women who sought family planning services were adolescents, yet $86 \%$ $(27 / 32)$ facilities reported that they provide services to married people. Seventy three percent (24/32) mentioned that there is an age limit below which they cannot offer Family Planning (FP) services to young people for all methods without spousal or parental approval. None of the facilities had adolescent guidelines or policy documents while only $13 \%$ (4/32) facilities had peer education and counseling programs.

The health workers and district management reported the lack of training of all staff in adolescent health as a hindering factor as noted in the quotes below:

An organization in 2004, trained few health workers but now you know we have had transfers in and out. So I think most of the health workers in the facilities currently are not trained because people who were trained were given transfers to other parts of the district. Lack of training affects the way health workers interact with adolescents who seek care during different working shifts. (Key informant, District Health team)

There is still a need of training staff in those facilities to know how to handle adolescents or youths. Some staff members are rude to them and these people if you are rude to them, they don't come back again, so there is a need of training for the health workers especially those looking after these adolescents. (Key informant, Nurse, In-charge HCII)

\section{Discussion}

Based on the selected parameters used, the overall finding of this paper is that most health facilities in Wakiso district were not adequately prepared to offer reproductive health services that meet the needs of young people. Many of the facilities were not accessible by public transport while hours of operation were not convenient to young people. Many facilities also lacked adequate space that would provide young clients with privacy. Besides, the facilities lacked adequate medical supplies and equipment. In spite of these shortcomings, a substantial proportion of young people sought SRH services from the facilities.

Available evidence indicates that health facilities in rural areas are characterized by poor physical accessibility due to long distances that individuals seeking care have to travel. This is in congruency with findings from another study which revealed many rural health facilities had poor physical accessibility due to 


\section{Global Journal of Reproductive Medicine}

their location [23]. Young people tend to be affected more than the general population by distances to health facilities mainly because they depend on adults for economic support and may lack money to cater for transport costs if they have to travel long distances to receive care [5].

Poor physical accessibility can be mitigated by conducting outreach visits to young people in the rural settings. Challenges with outreach services are the additional costs of delivering services in terms of transport and intensive mobilization. However, if outreaches are to be effective, they have to be implemented consistently in order not to disappoint clients [24].

Another finding of the paper is that a substantial proportion of young people seeking services from health facilities $\mathrm{w}$ ere adolescents aged 10-19 years. Consistent with findings from elsewhere [5-6, 23-25] the services that adolescents mostly sought were antenatal care, delivery care, contraceptives, and treatment for sexually transmitted infections. The study found that a high number of adolescent mothers were making the first antenatal care visit, which could partly be due to early marriage and non-use of contraception. Findings from the 2011 Uganda Demographic and Health Survey, for instance, show that among women aged 20-49 years, 15\% were married by age 15 .

While $49 \%$ were married by age 18 [8]. In addition, only $13 \%$ of currently married women aged $15-19$ years were using modern methods of contraception [8].

"Unlike antenatal care, the proportion of young people seeking post-abortion care was low although $\mathrm{m}$ any were not using contraception. Non-use of contraception by sexually active young people is associated with unwanted pregnancies that mostly result in unsafe abortions [26]. Studies show that some young people do not seek services following an abortion [27] which could partly explain the low proportion of young people that sought post-abortion care services in our study. Available evidence indicates that young people avoid seeking services from local health facilities for various reasons including lack of com m unity support, unreliable means of transport, and bad experiences at the facility due to maltreatment by staff [28].

We further found that few young mothers sought postnatal care. Postnatal care is important for improving both the health of the mother and the baby as it provides opportunity for detecting any complications that could lead to maternal or infant morbidity or death, immunizing the baby against common illnesses, counseling them other on proper infant feeding practices and self-care, as well as providing family planning information and services [29]. The finding of the paper therefore suggests the need for improving the uptake of postnatal care services among young mothers to reduce the chances of maternal and infant morbidity and mortality among this segment of the population.

As demonstrated elsewhere [5,23] young people have preferred visiting hours to health facilities. The reported preferred times in this study tend to be hours when the majority of adults have already sought care and therefore there is "pseudo privacy". Adolescent preference to seek services in the absence of adults is related to fear of revealing sexual activity [5]. Opening clinics during hours when young people can conveniently attend is highly recommended for effective recruitment into programs. In addition, this approach is more likely to attract adolescents in school who are reluctant to take time off during official class hours to utilize preventive services. Provision of services during hours that are convenient to young people could be achieved through recruiting and training service providers on youthfriendly services to work in shifts.

Facilities that were included in the study lacked rooms for ensuring the privacy of young people. Health facilities in Uganda tend to be more congested in the morning hours. Young people need to be assured of privacy during consultations and confidentiality afterwards [5,30]. The lack of privacy at health facilities is further compromised if the young people are required to seek services at the same time as adult clients. This is likely to deter them from utilizing health services. Training all health providers on youth friendly services and having them work in shifts is one strategy to ensure continuity of service delivery to all young people whenever they come to the facilities.

The finding suggests the need for the Uganda Ministry of Health to ensure that health facilities have adequate equipment and supplies to meet the reproductive health needs of young people as stipulated in the Adolescent Health Policy Guidelines and Service Standards [19]. Moreover, none of the health facilities included in the study had the guidelines. Absence of the guidelines at the health facilities coupled with limited training in adolescent health may greatly affect the quality of services that young people receive. For instance, most of the health facilities reported that they provide contraceptives to married individuals only contrary to what is stipulated in the Adolescent Health Policy Guidelines that young people should be granted access to reproductive health information and services that they need. There is therefore need to disseminate the guidelines and to train health care workers in service provision for young people.

In addition, the lack of Peer Educators (PEs) may contribute to the limited range of services offered at various facilities. For example many facilities lacked counseling services for the young people yet the PEs can address this gap once trained and facilitated. Educational support facilities such as posters, brochures and other print materials were scarce. Such educational materials if available may complement the educational activities offered by the few health providers and PEs at the facilities.

Facilities included in the study lacked a form al referral system involving back-and-forth communication between clinical practitioners. A robust referral system needs to be established to ensure that young people are better managed through tracking and close follow-up visits. However, establishing a robust referral system requires more investment in training of health workers. 


\section{Global Journal of Reproductive Medicine}

Importantly, the findings should be interpreted with caution as the study had limited geographical coverage. Thus the findings may not be generalized to the entire country since it was conducted in one district. In addition use of records has challenges of missing and incomplete data. However the record findings were triangulated with key informant interviews.

\section{Conclusion}

Young people in Wakiso district of Uganda face many barriers to accessing health care services. The barriers include geographical inaccessibility, inconvenient operating hours, lack of privacy and inadequate supplies. Reducing these barriers is necessary for enabling rural health facilities in the country to provide youth-friendly reproductive health services. There is also need to train all health care providers and peer educators in service provision for young people. In addition, the existing guidelines should be disseminated and distributed to all health facilities.

\section{Acknowledgement}

This work was made possible by Medical Education for Equitable Services to All Ugandans a Medical Education Partnership Initiative grant number 5R24TW008886 from the Office of Global AIDS Coordinator and the U. S. Department of Health and Human Services, Health Resources and Services Administration and National Institutes of Health. Its contents are solely the responsibility of the authors and do not necessarily represent the official views of the US governmen. We also acknowledge the Wakiso district administration, Health workers in facilities, research assistants and our study participants. We are grateful to Dr. Harriet Kivumbi who supported editing and proof reading.

\section{Funding}

The study was funded by Medical Education for Equitable Services to All Ugandans Consortium (MESAU).

\section{References}

1. https://www.unfpa.org/sites/default/files/resource-pdf/One $\% 20$ pager\%20on\%20youth\%20demographics\%20GF.pdf

2. UNFPA (2007) Framework for Action on Adolescents and Youth UNFPA: New York p. 46.

3. United Nations (2011) United Nations Expert Group Meeting on Adolescents, Youth and Development New York.

4. Patton GC, Coffey C, Sawyer SM, Viner RM, Haller DM, et al. (2009) Global patterns of mortality in young people: a systematic analysis of population health data. Lancet 374(9693): 881-892.

5. World Health Organization (2002) Adolescent friendly health services: An agenda for change. WHO: Geneva p. 44.

6. Mngadi PT, Faxelid E, Zwane IT, Höjer B, Ransjo-Arvidson AB (2008) Health providers' perceptions of adolescent sexual and reproductive health care in Swaziland. Int Nurs Rev 55(2): 148-155.

7. United Nations (2012) MDG Report 2012. In. New York: United Nations; 2012.
8. Uganda Demographic and Health Survey 2011. Uganda Bureau of Statistics and ICF International Calverton, Maryland, USA Uganda Bureau of Statistics Kampala, Uganda.

9. Dickson-Tetteh K, Pettifor A, Moleko W (2001) Working with public sector clinics to provide adolescent-friendly services in South Africa. Reprod Health Matters 9(17): 160-169.

10. WHO, Quality assessment guidebook: a guide to assessing health services for adolescent clients., in WHO Press, , W.H.O. (WHO), Editor 2009: 20 Avenue Appia, 1211 Geneva 27, Switzerland.

11. Anne W Kamau (2006) Factors influencing access and utilisation of preventive reproductive health services by adolescents in Kenya: a case study of Murang'a District.

12. Pamela M Godia, Joyce M Olenja, Joyce A Lavussa, Deborah Quinney, Jan J Hofman, et al. (2013) Sexual reproductive health service provision to young people in Kenya; health service providers' experiences. BMC Health Services Research 13: p. 476.

13. Feleke SA, Koye DN, Demssie AF, Mengesha ZB (2013) Reproductive health service utilization and associated factors among adolescents (15-19years old) in Gondar town, Northwest Ethiopia. BMC Health Serv Res 13: p. 294.

14. Biddlecom AE, Munthali A, Singh S, Woog V (2007) Adolescents' views of and preferences for sexual and reproductive health services in Burkina Faso, Ghana, Malawi and Uganda. Afr J Reprod Health 11(3): p. $99-110$

15. Chandra-Mouli V, McCarraher DR, Phillips SJ, Williamson NE Hainsworth G (2014) Contraception for adolescents in low and middle income countries: needs, barriers, and access. Reprod Health 11(1): p.

16. Dickson-Tetteh K, Ladha S (2000) Youth Health: South African Health Review. Health Systems Trust: Durban. p. 393-409.

17. Mngadi PT, Faxelid E, Zwane IT, Höjer B, Ransjo-Arvidson AB (2008) Health providers' perceptions of adolescent sexual and reproductive health care in Swaziland. Int nurs rev 55(2): p. 148-155.

18. Van Rossem R, Meekers D (2000) An evaluation of the effectiveness of targeted social marketing to promote adolescent and young adult reproductive health in Cameroon. AIDS Educ Prev 12(5): 383-404.

19. Mo H (2012) The Adolescent Health Policy Guidelines and Service Standards. Ministry of Health: The Reproductive Health Division, Department of Community Health.

20. Ministry of Health (2010) Health Sector Strategic and Investment Plan. 2010-2015, Planning, Editor Government of Uganda p. 202.

21. Uganda Bureau of Statistics (UBOS) (2012) Statistical Abstract, UBOS, Editor. 2012, Government of Uganda. p. 288.

22. WHO (2009) Quality Assessment Guidebook: A guide for assessing health services for adolescent clients. 2009, World Health Organization: Geneva ,Switzerland

23. Dickson-Tetteh K, Pettifor A, Moleko W (2001) Working with public sector clinics to provide adolescent-friendly services in South Africa. Reprod Health Matters 9(17): p. 160-169.

24. Eric de Roodenbeke (2011) Outreach Services as a Strategy to Increase Access to Health Workers in Remote and Rural Areas. Technical Report 2 World Health Organization Switzerland.

25. Ngarambe Faustine (2005) Appraisal of adolescent reproductive health services in Jinja. Uganda Martyrs University.

26. Eliason S, Baiden F, Quansah-Asare G, Graham-Hayfron Y, Bonsu D, et al. (2013) Factors influencing the intention of women in rural Ghana to adopt postpartum family planning. Reprod Health 10: p. 34. 
27. Elena Prada, Florence Mirembe, Fatima H. Ahmed, Rose Nalwadda, Charles Kiggundu (2005) Abortion and postabortion care in Uganda: A Report from Health Care Professionals and Health Facilities. Occasional Report No.17.

28. Fetters T, Tesfaye S, Clark KA (2008) An assessment of postabortion care in three regions in Ethiopia, 2000 to 2004. Int J Gynaecol Obstet 101(1): p. 100-106.
29. Curtis C, Huber D, Moss-Knight T (2010) Postabortion family planning: addressing the cycle of repeat unintended pregnancy and abortion. Int Perspect Sex Reprod Health 36(1): 44-48.

30. Berg-Kelly K (2003) Adolescent-friendly services. Acta Paediatr 92(11): 1241-1242.
This work is licensed under Creative Commons Attribution 4.0 License DOI: 10.19080/GJORM.2017.02.555588 